\title{
A STUDY OF 25 CASES OF COMPRESSION OF THE CAUDA EQUINA BY PROLAPSED INTERVERTEBRAL DISCS
}

\author{
BY \\ W. BRYAN JENNETT \\ From the Department of Neurological Surgery, Radcliffe Infirmary, Oxford
}

\begin{abstract}
Most cases of sciatica due to intervertebral disc lesions are in fact partial cauda equina lesions. Commonly they are unilateral and there is muscular weakness, wasting, reflex abnormalities, and sensory impairment referable to compression of one or more roots. These defects are rarely disabling in themselves and are of importance chiefly in diagnosis and localization. In some cases the weakness may amount to complete paralysis of the anterior tibial group of muscles and a drop foot results. In a smaller number there are profound bilateral signs : total distal paralysis of the lower limbs, sensory loss in the whole sacral distribution, and sphincter paralysis. This is one type of lumbar disc lesion which does not respond to conservative treatment, and it is the only type which may constitute a threat to life. It is remarkable that it has not figured more prominently in the vast literature which has accumulated since Mixter and Barr (1934) "discovered" the intervertebral disc lesion 22 years ago.
\end{abstract}

The largest number reported together is eight, described by Ver Brugghen (1945) with one fatal but unverified case. There are other isolated cases in the literature of which I have collected 34 with verified lesions and with sufficient data to make some useful comparisons with the present series. (Dandy, 1929 and 1942; Eyre-Brook, 1952; French and Payne, 1944 ; Kaplan and Umansky, 1951; Kennedy, Hyde, and Kaufman, 1948; Nicaud, 1947 ; O'Connell, 1944 ; Rouqués, David, and Pautrat, 1948 ; Schneider, 1949). This paper reports a further 25 verified cases, which were treated in the Radcliffe Infirmary and associated hospitals in Oxford between 1937 and 1955, during which time about 1,000 cases of lumbar disc lesion were verified at operation. Although the incidence is thus about $2 \%$ in the surgical material (similar to that found by Ver Brugghen), the actual incidence of cauda equina paralysis in all lumbar disc lesions is clearly not so high because almost all cases of cauda equina compression are operated on, whereas only a small proportion of cases of sciatic pain presumed to be due to disc lesions are dealt with surgically and so verified.

Paralysis of the cauda equina may be the first significant manifestation of a lumbar disc lesion, although more commonly it is a sudden complication of an attack of " ordinary" sciatica, either an initial attack or one of a series of recurrent attacks. Two types of lesion have been encountered. In the first there is a massive protrusion of the disc which takes up all the available room in the vertebral canal and behaves much like a large extrathecal tumour. In other cases the disc protrusion is smaller, by no means large enough to fill the vertebral canal or crush the cauda equina and often of the type seen in cases of uncomplicated sciatica, but it is associated with a well demarcated band of dense adhesions within the theca which strangle the roots of the cauda equina.

Case 1.-A. H., a man, aged 56 (R.I. 7352/40), 20 years before admission had an attack of backache and left-sided sciatica for two weeks. In the 18 months before admission he had three or four attacks of right-sided sciatica with backache, and four months before admission an attack proceeded to bilateral sciatica. The morning after this he woke with complete double sphincter paralysis and the right leg useless and numb. He had developed decubitus ulcers on one buttock and both heels two to three weeks before admission.

On arrival he was toxic, pyrexial, and hiccoughing, the blood urea being $140 \mathrm{mg} . / 100 \mathrm{ml}$. He could not move the right leg against gravity whilst paralysis was complete below the knee; there was distal weakness and wasting in the left leg. Sensory loss was asymmetrical, involving the saddle area and on the right L.4 and L.5 dermatomes as well. The ankle jerks were absent and he had retention of urine (with infection) and a patulous anal sphincter. The C.S.F. protein was 600 $\mathrm{mg}$. $/ 100 \mathrm{ml}$. and the fluid was xanthochromic ; myelography showed a block at L.2-3 interspace.

The patient died of uraemia a fortnight after admission without having been operated on, and at necropsy a small disc protrusion was found compressing the right third lumbar root. This lesion appeared to be too small to have accounted for the paralysis, but on opening the theca there was found to be a dense and sharply de- 
marcated band of arachnoid adhesions exactly opposite the disc protrusion. This band was lightly adherent to the inner aspect of the dura, but the roots of the cauda equina were firmly embedded in it and could only be isolated by sharp dissection. Above and below this band the leptomeninx appeared to be normal.

This type of lesion, which is less common than the massive prolapse, is also seen in association with disc lesions in other parts of the vertebral canal, for example, in the cervical region where some authors regard it as important in the myelopathy associated with cervical spondylosis. Pathologically, it may be thought of as a "friction arachnoiditis ", and, although a chronic process, paralytic symptoms may develop just as suddenly as when a massive protrusion is present (Stookey, 1927). The primary pathological process, the protrusion of the disc into the vertebral canal, must be similar to that in ordinary sciatica but differing in some cases in size and in some in the tendency for adhesions to develop around the nerve roots within the theca. This study was undertaken to see whether any reason could be found for some cases behaving in this serious manner, whether any steps could be taken to prevent it, and what the results of treatment were. It will be seen that the first two objectives have succeeded only to a very limited extent. It will also be seen that the term "compression" is used as a convenient description of the syndrome, although not all the cases were subject to actual compression by a massive protrusion.

\section{Analysis of Cases}

Fifteen of the patients were men, 10 were women, The youngest was 20 years old, the eldest 72 , and the remainder about equally distributed between the fourth, fifth, and sixth decades. Compression of the cauda equina thus occurs rather later than the uncomplicated sciatic pain which usually leads a patient to seek advice for a disc lesion.

In 14 cases there was a history of repeated attacks of backache and sciatica for many years. There was nothing very unusual about these attacks, although in two cases the sciatic pain had been bilateral and in two others it had alternated between the two sides. In most cases the final attack began just as the previous ones had done, although it usually developed into the most painful attack yet experienced. In one case the paralysis occurred four years after an operation for a disc protrusion at the same level.

In 11 cases the cauda equina symptoms occurred in the first attack. In one case there had been continuous back pain and sciatica for 12 months before the onset of cauda equina paralysis, but usually it was a much shorter period, the shortest being three weeks. In two patients in this group the lesion was related to pregnancy and the puerperium: in one, back pain and sciatica began in the fourth month of pregnancy and were followed a mon later by symptoms of cauda equina compressionu in the other, back pain and sciatica began in the third week of the puerperium and were followed two months later by compression symptom. O'Connell (1944) described four cases in the puerperium.

In 12 cases the onset of compression was sudderif; in the remainder it was rapid, complete paralysis developing over a few days. In these latter cases the march of events simulated inflammatory lesiops such as epidural abscess or even a rapidly growing tumour.

When the onset is sudden, it might be expected that it would be attributed to some sudden move ment, strain, or other injury but that was so in on three cases, whilst in four other cases, by contrast, the paralysis came on whilst the patient was restireg in bed. Of the former three cases one developed sphincter paralysis during a game of crickett another gave a violent cough whilst in bed sciatica and was immediately aware of numbaress and paralysis of both legs and had sphincter palysis, whilst the third patient had a profound ca্łda equina paralysis immediately after manipulatio 8 the back for long-standing sciatica.

Case 2.-J. B., a woman aged 33 (R.I. 16687), ha영 attack of right-sided sciatica at the age of 16 years. It persisted in greater or less degree for three years, aw she was then completely free from symptoms for years until 10 months before admission when, followie a mild back strain, there was a gradual recurrence off pain in the back and down the posterior aspect of bodi lower limbs. Despite various forms of physiotherapy, the pain persisted and after eight months she was bedridden with it. Three weeks before admission, the lumbår spine was manipulated under general anaesthesia. recovering from the anaesthetic, she was free from pain, but complained of numbness and weakness of the legs; and was unable to empty the bladder.

On examination there was gross distal paralysis both lower limbs, affecting all the muscles supplied By the lowest lumbar and all the sacral nerve roots. The knee jerks were present, the ankle jerks absent, as al were the plantar responses. There was deep sensory loss along the lateral border of the feet, on the posterigr aspects of the legs and thighs, over the buttocks and perineum, that is, the areas supplied by the fifth lumbs and all the sacral roots. There was retention of urine ang incontinence of faeces, with loss of the anal reflex. The cerebrospinal fluid contained $200 \mathrm{mg}$. protein $/ 100 \mathrm{ml} . \mathrm{N}$

There seemed to be clear evidence of compression the cauda equina and at operation a large protrusion $\frac{\delta}{\partial}$ the lumbo-sacral disc was removed. 
Recovery was slow. Improvement in motor power and sphincter control continued for three years, but when last seen nine years after operation, the patient still had a slightly waddling gait and also sensory loss. The vesical sphincter had improved to the point where by taking care she could avoid incontinence, but there was still occasional rectal incontinence.

\section{Symptomatology}

Pain.-As noted above practically all these patients had pain of greater or less degree before the onset of paralysis, and in character and distribution it resembled that of the common lumbar disc lesion. It is significant, however, that 14 patients had bilateral sciatic pain in the paralytic attack, although it was usually much more severe on one side than the other. It is also interesting that four patients experienced sudden and dramatic relief of pain with the onset of paralysis. I have known this to occur in many cases of sciatica with the onset of a drop foot and it must mean that severe compression has abolished pain conduction as completely as that of the motor impulses.

Two patients had very little pain, and the diagnosis in such cases may be very difficult. One of these patients awoke one morning with a profound cauda equina paralysis and only on subsequent questioning would he admit to having had, for three weeks before the onset of paralysis, slight discomfort in the back and in the right sciatic distribution. A disc protrusion was found at L.5-S.1. The other case was very unusual in having had little pain and no demonstrable sensory loss.

Case 3.-E. F., a man aged 52 (R.I. 82610/47), was referred because of the discovery of a high protein content in the C.S.F. in the course of investigation for retention of urine.

The story was that 10 years previously he had suddenly developed incontinence during a game of cricket. This cleared up, except for stress incontinence, within a few days. Eight months before admission he developed chronic retention with overflow and a month later an attack of acute retention led to emergency admission to another hospital. A suprapubic cystostomy was done and he returned to work as a gardener. At a subsequent admission to see if any cause could be found for the sphincter paralysis, a lumbar puncture revealed a great excess of protein in the cerebrospinal fluid and he was accordingly referred for a neurosurgical opinion.

This patient denied having had sciatic pain at any time, but he had had mild lumbago five years previously which had neither incapacitated him nor led to his seeking medical advice. His bowels moved normally with no incontinence, and sexual functions were normal.

On examination, the patient was a healthy looking man. He had learned to manage the suprapubic cystostomy so that it was only a minor inconvenience. Movements of the lumbar spine were normal, and there was no demonstrable weakness of the lower limbs. The reflexes were normal except that the left ankle jerk and the left cremasteric reflex were absent. There was no demonstrable sensory defect. Radiographs of the vertebral column were normal. Lumbar puncture in the fourth lumbar space revealed a manometric block, and the cerebrospinal fluid contained $520 \mathrm{mg}$. protein $/ 100$ $\mathrm{ml}$. Myelography demonstrated an obstruction opposite the second lumbar disc. At operation a small calcified protrusion of the second lumbar disc was found. It was obviously too small to cause compression of the theca and its contents, but on opening the theca a dense band of fibrous thickening of the arachnoid was found. It was so thick and opaque that the roots of the cauda equina could not be seen through it, although above and below this lesion the leptomeninx looked normal.

Five years after operation he reported no significant change, but said that he had had some back pain and right-sided sciatica at times, but it was in no way disabling.

Paralysis of Muscles.-In 11 cases there was profound paralysis. This usually involved the anterior tibial and peroneal groups and the calf muscles, although in some cases one group was affected more than another and the legs were involved asymmetrically. The functional effect was profound paralysis of the legs and feet, and if an incomplete lesion it was usually a unilateral or bilateral foot-drop. In six cases there was no significant motor paralysis, in which cases the disturbance was limited to sensory and sphincteric functions.

The ankle jerks were absent on both sides in 16 cases, on one side in six; in a single case both were present although they were previously known to have been absent.

Sensation.--In all but one case (Case 3 above) there was objective sensory loss, characteristically in the whole sacral distribution and involving all modalities. When the sensory defect was so complete and extensive, the patients were often aware of numbness, but in some cases they did not seem to have noticed it until their attention was called to it. In 11 cases the sensory loss was less complete and was often asymmetrical, that is, there was complete loss in the whole sacral distribution on one side but in the other side the loss was limited to the perianal and perineal region. In five cases the loss was confined to a small area around the anus and in the perineum. Such cases emphasize the importance of a complete sensory examination, as it may provide the only objective evidence of a neurogenic cause for sphincter paralysis.

Sphincters.-Some degree of paralysis of the anal and vesical sphincters occurred in all but two of the 25 cases. In 14 it was complete with retention of 
urine and a patulous anal sphincter leading usually to faecal incontinence. In the rest there was something short of this, for example, intermittent retention, loss of vesical and urethral sensation, or constipation with defective anal sensation. Complete (double) sphincter paralysis was always accompanied by profound bilateral sensory loss in the saddle area, often in the whole sacral distribution. In some of these cases there was a remarkable escape of motor power, that is, the patient had complete sphincter paralysis, extensive sensory loss, absent ankle jerks, and yet no muscular paralysis. We have encountered only one case of significant sphincter paralysis due to a disc lesion in which the sensory and motor defects were strictly unilateral, whilst in Case 3 (above) the paralysed bladder was accompanied by neither motor nor sensory deficit. That sphincter paralysis is so common a feature in this series is understandable because it is usually this complication which leads to their admission to hospital: although the preceding pain may have been the most severe yet experienced, the patient and his doctor are familiar with it, and defects in sensation and motor power may not be very obtrusive when the patient is already in bed. But everyone appreciates the gravity and inconvenience of sphincter paralysis and there is usually no delay in seeking admission to hospital once it occurs. And it is often this symptom alone which demands operation, that is, the pain has often cleared up and the sensory and motor deficits are not enough in themselves to warrant operation.

\section{Investigations}

Plain Radiographs.-As in other cases of intervertebral disc lesions, radiographs were of value chiefly in excluding other causes of cauda equina compression, such as intraspinal tumour. In seven cases there was some narrowing of the appropriate disc space, and in six others there were local arthritic changes, but in none were the radiological features regarded as diagnostic.

Lumbar Puncture.-As the majority of these lesions occur in the fourth and fifth lumbar discs, lumbar puncture at the usual site (third or fourth interspace) will often be above the lesion. Even so, in each of the 21 patients from whom fluid was obtained there was an increase in the protein content. This varied from 55 to $590 \mathrm{mg}$. $/ 100 \mathrm{ml}$., with more than $100 \mathrm{mg}$. in 15 cases. In three patients specimens were obtained from both above and below the lesion, and a manometric block was demonstrated between the two sites of puncture. In two of these the fluid was xanthochromic both above and below the lesion, the protein content being $500 \mathrm{mg}$. in both specimens in one case and $590 \mathrm{mg}$. below and $100 \mathrm{mg}$. above in the othe In the third case the values were $70 \mathrm{mg}$. above and $90 \mathrm{mg}$. below. It was not possible to correlate the variations in the protein content of the fluid witto either of the two types of lesion encountered operation. It might have been supposed, fo instance, that the cases in which there was fibrow thickening of the arachnoid would have shown higher protein contents in the fluid whether frop above or below the lesion, but that was not cops stantly so : indeed both the highest and the lowe protein contents were found in cases with marke arachnoid thickening.

In all cases in which the puncture was done below the lesion, a partial or complete manometrfe block was found. In two cases repeated efforts failed to obtain any fluid, a common experience with other expanding lesions of the cauda equina.

Myelography.-This was done in 18 cases, in $\overline{\overline{\mathbf{m}}}$ of which there was a complete obstruction to the passage of the opaque medium. In most there was an irregular margin at the site of the obstruction, suggesting an extrathecal lesion, but in two cass there was a smooth, rounded margin as is commos़ी seen with intrathecal neoplasms. The opaque sur $\mathrm{b}^{-}$ stance was in each case introduced into the lumbar theca, either above or below the lesion, and toum either the upper or lower margin of the lesion as demonstrated.

\section{Findings at Operation}

With the exception of Case 1, all patients were operated on. The site of the lesions is indicated i⿱乛龰 Table I.

TABLE I

SITE OF LESION

\begin{tabular}{|c|c|c|}
\hline Lumbar Disc & Cases in Series & Reported Cases \\
\hline $\begin{array}{l}1 \\
2 \\
3 \\
4 \\
5\end{array}$ & $\begin{array}{l}\overline{1}(+ \text { case } 1) \\
3 \\
10 \\
12\end{array}$ & $\begin{array}{r}1 \\
5 \\
11 \\
11 \\
6\end{array}$ \\
\hline & $26^{*}$ & 34 \\
\hline
\end{tabular}

* In two cases lesions were found at both fourth and fifth spaces.

It will be noted that 22 of the 26 lesions occurreg at the common sites associated with uncomplicated sciatica. In the two cases with double lesions was the two lower spaces that were affected.

In 17 cases there was a massive loose fragmerft largely filling the vertebral canal, behaving muck as an extrathecal tumour. In the remainder the protrusion although large was no larger than often seen in cases of ordinary sciatica, but in each 
of these the theca was opened and focal thickening of the arachnoid was found. In these cases the changes in the arachnoid seemed to be of more importance than the size of the disc lesion. It is interesting that the patients with arachnoid changes had on the whole no longer histories than those without such changes, and that in three of them, without any massive disc protrusion, the onset of the cauda equina syndrome was sudden.

These arachnoid changes may also account for persistence of a myelographic obstruction after the protruded disc material has been removed. This is not surprising, as it is unlikely that removal of an extrathecal mass would have any immediate effect on structural changes within the theca. That a clinical problem exists, however, is demonstrated by the following case.

Case 4.-B.C., a woman aged 27 (R.I. 186976/54), had suffered from six attacks of back pain each of a week's duration since a trivial back strain six years previously. Three weeks before admission bilateral sciatica supervened in one of her attacks. A fortnight later she awoke to find weakness and numbness of the legs and she had retention of urine.

On examination there was a profound flaccid weakness of both legs, but the paralysis was not quite complete, that is, there were feeble movements of the toes and ankles. The ankle jerks were absent and there was sensory loss below L.5. Puncture at the L.4-5 interspace revealed no manometric block and the C.S.F. protein was $65 \mathrm{mg} . / 100 \mathrm{ml}$. Myelography (from below) showed a complete block at L.3-4, however.

At operation a moderate-sized lesion was removed from the L.3-4 level extrathecally. There was no immediate improvement but in fact some deterioration in motor power. She was screened again the day after operation and the opaque medium was found to be immobile. Subsequently a cisternal injection was made but this too was completely held up at the site of the original lesion. It was decided to re-explore lest a fragment of disc had been missed and this was done 14 days after the first operation. No disc material was seen so the theca was opened and the arachnoid was found adherent to it. There was no subarachnoid space, only a little loculated C.S.F., and the roots were adherent to the arachnoid. No attempt was made to separate the roots. Progress from that time was very slow.

Although persistence of a myelographic abnormality after operation may thus be due to arachnoid adhesions, the possibility of there being two lesions must be remembered. In one case in the present series, a persistent defect led to re-exploration with the discovery of a second lesion at the space below that originally explored.

\section{Post-operative Course and Long-term Follow-up}

In addition to Case 1, who died unoperated, one patient died nine days after operation from un- associated pathology, though operation doubtless initiated her final collapse (Case 5). All the remaining patients have been followed up since their discharge from hospital, some for as long as 14 years. Only four of them have made complete recoveries as regards muscular power, sensation, and sphincter control.

It is widely known that recovery from cauda equina lesions is slow but it is doubtful if it is realized just how unsatisfactory it can be. In general the motor recovery is better than the sensory and all the surviving patients are walking again. Once the compressing lesion has been removed motor recovery occurs slowly by regeneration, as in a peripheral nerve damaged in continuity. As O'Connell (1950) has pointed out, the sensory lesion in these cases is proximal to the posterior root ganglion and if it is severe enough to cause degeneration there can be no improvement. That some sensory recovery occurs is due to the fact that at the outset the lesion is not complete and some partially damaged roots ultimately recover. Sphincter paralysis is often the most serious aspect of the problem for obvious reasons, and a patient may become fully ambulant, free of pain, and in no way inconvenienced by sensory loss, yet still not have adequate control of the sphincters. It may be three or four years before the end state in regard to sphincter control is reached, and the patient will need a good deal of encouragement and reassurance during this time, in addition to careful observation of the urine to ensure that chronic infection does not do irreparable damage.

Of the few who still had back pain or sciatic pain at the time of operation, all were relieved immediately, and there has been no recurrence of pain except in Case 3 in which there was profound arachnoid thickening. In general, the patients with arachnoid changes recovered more slowly and less completely than those in whom there was a massive compressing lesion without arachnoid changes.

Paralysis of the limb muscles may persist for two to three months after operation before there is any sign of recovery, and improvement once started continues only very slowly. It is difficult to assess the rate of progress but it appears that the greatest improvement occurs in the first two years after operation, although several patients have professed continuing improvement after as along as five years. Some of this protracted improvement is probably due to the patient learning to make better use of permanently weakened muscles, as occurs in other cases of static paralysis. Of the seven patients who have left hospital having had significant paralysis before operation only two have made complete 
motor recoveries. All the remainder are fully ambulant, however, most of them with only a slight limp. The ankle jerks were still absent at the most recent examination in 11 cases, while in two others they returned at the second and third year respectively.

Sensation usually recovers more slowly and less completely than motor power, and it was possible to demonstrate some impairment in the preoperative distribution in 11 cases up to nine years later. The loss is commonly less profound and extensive, however, and usually causes no inconvenience. None of the patients is known to have developed trophic changes.

Of the 14 patients who had total paralysis of the bladder and bowel before operation and have left hospital, only two have regained full control and sensation (Table II). Seven acquired full control of

TABLE II

DEGREE OF RECOVERY IN 14 CASES IN THIS SERIES WITH COMPLETE DOUBLE SPHINCTER PARALYSIS

\begin{tabular}{|c|c|c|c|c|c|}
\hline $\begin{array}{l}\text { Case } \\
\text { No. }\end{array}$ & $\begin{array}{l}\text { Compression- } \\
\text { operation } \\
\text { Interval }\end{array}$ & Bladder & Bowel & $\begin{array}{c}\text { Sexual } \\
\text { Function }\end{array}$ & $\begin{array}{l}\text { Length of } \\
\text { Follow-up } \\
\text { (yr.) }\end{array}$ \\
\hline $\begin{array}{r}1 \\
3 \\
5 \\
7 \\
9 \\
11 \\
12 \\
14 \\
15 \\
16 \\
17 \\
23 \\
20 \\
25\end{array}$ & $\begin{array}{l}1 \text { month } \\
3 \frac{1}{2} \text { weeks } \\
2 \text { weeks } \\
3 \text { months } \\
1 \text { week } \\
2 \text { weeks } \\
3 \text { days } \\
3 \text { weeks } \\
2 \text { months } \\
2 \text { weeks } \\
2 \text { weeks } \\
2 \text { weeks } \\
1 \text { week } \\
7 \text { months }\end{array}$ & $\begin{array}{l}F \\
F \\
G \\
F \\
P \\
\text { VG } \\
\text { G } \\
\text { VG } \\
\text { G } \\
\text { G } \\
\text { G } \\
\text { G } \\
\text { VG } \\
\end{array}$ & $\begin{array}{l}F \\
F \\
F \\
G \\
G \\
\text { VG } \\
G \\
F \\
G \\
P \\
N M \\
G \\
\text { VG } \\
\end{array}$ & $\begin{array}{c}\text { - } \\
\text { Impotent } \\
\text { Normal } \\
\text { Normal } \\
\text { E- } \\
\text { Normal } \\
\text { - } \\
\text { - } \\
\text { - }\end{array}$ & $\begin{array}{l}13 \\
2 \\
4 \\
5 \\
5 \\
5 \\
5 \\
5 \\
9 \\
13 \\
4 \\
1 \\
1 \\
14 / 12 \\
\text { Nil }\end{array}$ \\
\hline
\end{tabular}

VG $=$ perfect.

$\mathbf{G}=$ perfect control, no incontinence, but imperfect sensation. $F=\begin{gathered}\text { occasional } \\ \text { cautions. }\end{gathered}$

$P=$ requires appliance.

$\mathrm{NM}=$ no mention.

TABLE III

POST-OPERATIVE COURSE (CASES IN THIS SERIES AND FROM LITERATURE WITH SUFFICIENT INFORMATION)

\begin{tabular}{|c|c|c|c|c|c|}
\hline $\begin{array}{l}\text { Degree of } \\
\text { Recovery }\end{array}$ & & Perfect & $\begin{array}{l}\text { Perfect } \\
\text { Control }\end{array}$ & $\begin{array}{l}\text { Occasional } \\
\text { Incontin- } \\
\text { ence }\end{array}$ & $\begin{array}{l}\text { Requiring } \\
\text { Appliance }\end{array}$ \\
\hline $\begin{array}{l}\text { Motor } \\
\text { Present series } \\
\text { Literature } \\
\text { Total . . } \\
\text { \% (of total) }\end{array}$ & $\begin{array}{l}. \\
\cdots \\
\cdots\end{array}$ & $\begin{array}{r}8 \\
8 \\
16 \\
37\end{array}$ & $\begin{array}{r}3 \\
8 \\
11 \\
26\end{array}$ & $\begin{array}{r}2 \\
9 \\
11 \\
26\end{array}$ & $\begin{array}{r}2(=15) \\
3(=28) \\
5(=43) \\
12\end{array}$ \\
\hline $\begin{array}{l}\text { Bladder } \\
\text { Present series } \\
\text { Literature } \\
\text { Total . . } \\
\text { \% (of total) }\end{array}$ & $\begin{array}{l}\cdots \\
\cdots \\
\cdots\end{array}$ & $\begin{array}{r}6 \\
11 \\
17 \\
50\end{array}$ & $\begin{array}{r}6 \\
5 \\
11 \\
32\end{array}$ & $\frac{4}{4}$ & $\begin{array}{l}1(=17) \\
1(=17) \\
2(=34) \\
6\end{array}$ \\
\hline
\end{tabular}

the bladder and are never incontinent but they have defective vesical and urethral sensation and several are occasionally incontinent of faeces. The rest have occasional incontinence but in only two is this so frequent that an appliance has to be wor All but one have been followed for a year, and nine for over four years.

In general the bowel recovered less well than the bladder and there are only five patients who are not occasionally incontinent of faeces. In two of these the bowel has recovered more completely than the bladder.

Of the 14 males we have precise information about sexual activity in only four. One is impoter and three say they are normal. It is interesting note that in two of these recovery of the bladdes and bowel had been incomplete and there is sone: continuing defect in sensation in the lower sacr再 segments.

\section{Discussion}

Our experience accords fairly closely with the 34 other recorded cases which we have analysed. Igp these there was a striking preponderance of males and past middle life. Two cases followed a majo spinal injury without fracture, the diagnosis being made, in the presence of normal manometry, th myelography (Schneider, 1949). One case (Dardy 1929) followed therapeutic manipulation for bilat\&ri sciatica, a massive prolapse at L.3-4 being fo $\bar{g}$ ng subsequently. Three other cases (Ver Brugghen. 1945) of sudden onset were related to a vioter sneeze or cough, whilst a fourth patient (Tolosa 융셩 Ectors, 1953) related the onset of the cauda equim!s syndrome to stooping down to pick something the floor during an attack of sciatica. Two-thirds the patients had long histories of recurrent backach and sciatica and over half of them had bilatera sciatica in the compressing attack. Profour paralysis occurred in all but three, whilst the ank jerks were absent on both sides in 25 cases, on ore side in six and were present in two cases. Sensor $\overrightarrow{\vec{\theta}}$ loss in the saddle area was found in 24 of the 28 cases in which a sensory examination was recorde Complete sphincter paralysis is mentioned in 29 cases. A high protein content in the spinal fluid from below the level of the lesion is frequent found but there is no record of high values from above the lesion.

Myelography was done in 22 cases and in all $\underset{8}{8}$ them a gross lesion was demonstrated but the difficulty of differentiation between a disc lesio and a neoplasm seems to have been considerable French and Payne (1944) say that on the basis the myelogram five of their eight cases were operatend on with the diagnosis of tumour.

The site of the lesion in these 34 recorded cases shown in Table I. It will be seen that half were in the upper lumbar region as opposed to the common 
fourth and fifth lumbar discs, lesions which are responsible for the vast majority of uncomplicated cases of sciatica. Arachnoiditis was reported in three of one series of five cases operated on transdurally (Tolosa and Ectors, 1953).

It is difficult to assess the post-operative course in many of these cases because of insufficient data. It appears, however, that only four of the 34 made complete recoveries-an even smaller proportion than that in this series. (The results, reduced to standards as nearly as possible comparable to this series are set out in Table III, which shows that only 11 were followed for more than six months.) In regard to sphincter recovery, there are two features worthy of note. One is that in most cases there is no mention of the bowel, which we found to recover less well than the bladder. The other is that the number of "very good" recoveries of the vesical sphincter is probably too high, this designation having been awarded (by us) for such comments in the papers as "can control urine" or "bladder working again". Our experience in following up these patients for long periods is that they often minimise the shortcomings of the sphincters, so pleased are they to have them working at all. More than once there is a note in our records to say " bladder (or rectum) normal" and a later note by a more searching observer mentions significant defects present ever since the operation.

In the literature on spinal arachnoiditis there is little suggestion of a relationship with prolapsed disc until French (1946) reported 13 cases of localized lumbar arachnoiditis explored by operation in which a disc lesion was found in eight, whilst the remaining cases were early ones in which he thought it possible that a small disc lesion might have been missed. The general symptomatology of these cases was similar to those reported in our series but many were less severely disabled. The C.S.F. proteins were much lower than in our series whilst the recoveries seem to have been much less satisfactory with regard to relief of pain.

Several other points emerge from a consideration of our cases and those recorded in the literature. Compression of the cauda equina by intervertebral disc lesions is quite unpredictable although the possibility is slightly greater in patients of middle age and over. Bilateral symptoms and signs commonly precede serious compression and indicate its imminence. There is evidence too that a sudden movement may precipitate a compression lesion, and although we cannot avoid many such movements which occur in the course of daily life, to employ sudden or violent movement (for example, manipulation of the spine) as a therapeutic procedure seems to be risky. We are aware of the fact that the reported cases make up a very small proportion of the vast number of patients who have had manipulations for back pain and sciatica, but that this complication can occur and that it is quite unpredictable, makes us feel that manipulation should not be undertaken without due thought and knowledge of the risks. Eyre-Brook (1952) refers to a case and warns against manipulation. The question has obvious medico-legal importance.

Diagnosis is usually not difficult. The considerable elevation of the spinal fluid protein content may lead to the suspicion of a neoplasm, but the presence of a myelographic obstruction would indicate an exploration in either case. It should be mentioned that myelography is important in revealing the site of the lesion, as in five of these cases, and in half of those reported in the literature, the lesion was above the fourth and fifth discs, the ones usually explored in cases of sciatica. Myelography is also of value in indicating the presence of two lesions, one of which might not have been suspected from the clinical evidence.

One condition with which compression may be confused is the diabetic myelopathy described by Garland and Taverner (1953). The five patients described in their paper all had sciatic pain, muscle weakness, and absent tendon reflexes; four had raised protein in the C.S.F. None had any sensory loss, a useful but not reliable differentiating feature (see Case 3 of the present series), but in three cases there was at some time an extensor plantar response which would have ruled out a cauda equina compression. This problem of the possible relation between diabetes and cauda equina paralysis arose in one of our cases.

Case 5.-M.S., a woman aged 72 years (R.I. 198778/54), a moderately severe and poorly controlled diabetic of 12 years standing, had had an attack of left-sided sciatica six years before admission. Three weeks previously she had a recurrence followed after a week by gradual weakness of the left foot, then by numbness of the whole leg and a week before coming here she developed urinary retention.

She was still in severe pain with very limited spinal movement and straight leg raising diminished to $40^{\circ}$ on each side. There was an almost total palsy of the left foot with sensory loss in the entire sacral distribution on the left and in the lower sacral segments on the right as well. The protein content of the spinal fluid was $120 \mathrm{mg}$./ $100 \mathrm{ml}$. and there was a complete block at L.4-5 on the myelogram. The blood pressure was $220 / 110 \mathrm{~mm}$. $\mathrm{Hg}$ and the blood sugar $290 \mathrm{mg}$.

At operation a large loose fragment was found completely extruded from the disc space and several smaller ones still in the space. She was relieved of pain but there was no other striking change in her neurological state in the nine days during which she survived. She 
went gradually downhill, finally developing diabetic coma. At necropsy there were bilateral hypernephromata replacing most of the renal tissue, the blood vessels were in good condition, but the bladder was severely inflamed; there was no evidence of ascending urinary infection.

When operating for cauda equina paralysis some modifications of the technique used for uncomplicated cases of sciatica may be necessary. A more liberal exposure must be made, if necessary a full bilateral laminectomy, in order to see the lesion and avoid too vigorous retraction of the theca. If to approach the lesion extrathecally entails too much retraction (and in many of these cases the spinal canal is tightly filled) there must be no hesitation in opening the theca. The roots are then separated and the anterior theca over the bulge incised. As soon as the massive fragment, which is usually found in these very tight cases, is removed there is plenty of room and the exenteration of the disc space may be completed by the ordinary extrathecal approach. There is no need to close the incision in the anterior theca but that in the posterior is closed in the usual manner.

That operation for uncomplicated sciatica may not guarantee against a subsequent compressive lesion developing is shown by the following case.

Case 6.-C. N., a man aged 61 (R.I. 22631/42), first attended in 1942 when he was 57 . He had had bilateral sciatica and paraesthesiae in the sacraldistribution on and off for 10 years. At operation a moderate protrusion was removed from L.4-5 on the right. He made a complete recovery and remained well until 1946.

He returned then with the complaint that since " ricking his back" eight months previously he had suffered a gradual onset of backache and bilateral sciatica (worse on the right). Symptoms had been progressively worsening in the last four months and he had been in bed for two months, during which time he had noticed progressive weakness of the legs. Incontinence of faeces and hesitancy and difficulty with micturition had come on two weeks before admission.

There was marked bilateral palsy with wasting, including the buttocks, bilateral sensory loss in S.3, 4, and 5, and absent ankle jerks. Lumbar puncture at L.2-3 showed no block and the protein was $120 \mathrm{mg}$. $/ 100 \mathrm{ml}$.

At operation the dura was opened and matted bluishred roots were found stretched over a massive protrusion just to the right of the centre at L.4-5 (the site of the previous lesion); there was a massive free fragment. He left hospital six months after operation with little motor improvement but able to void in the sitting position. Within a year he could walk 40 yards without sticks, and a year later, according to a letter from him, was indulging in gardening and fishing.

This is the only instance that we know of in which serious compression has occurred after an operation for an intervertebral disc lesion. It is, however, an argument for a radical operation, if an operation $\overline{\mathrm{s}}$ to be done at all, for all lesions no matter ho simple. Removal of only the protrusion causing visible compression of a root is not sufficient a should be followed by vigorous exenteration of thg interior. In operating for ordinary uncomplicated sciatica we have found on many occasions lare loose fragments of annulus fibrosus in the interie which might well have been extruded subsequently had they not been removed at the time.

In these cases we found no evidence that the degree of recovery was related to the time interval between the onset of compression and the operation (see Tab $\overline{\bar{s}}$ II). Nevertheless there is everything to be said fo operation as soon as possible after the onset of paran lysis. Indeed an emergency operation in a rapidly progressive case might prevent complete paralysis? That is to say that a patient who has pain, incipient weakness, and sensory loss might be spared sphincte paralysis if operated on in time. It might also b. that the chances of arachnoid adhesions developing are lessened the sooner the compression is relievedo

Summary cases of cauda equina compression due to a verified prolapsed intervertebral disc 胥e described, including two fatal cases. The symeromatology, clinical details, and results of lumbar puncture and myelography are discussed, toget with the operative findings and follow-up afee leaving hospital.

Thirty-two further cases culled from the literature including one fatal but unverified case, are reviewedo

The incompleteness of recovery in most cases and the possibility of a fatal issue are stressece Attention is drawn to the risk of precipitating thif serious complication by manipulating uncomplicate $\mathbb{R}$ cases of sciatica believed to be due to prolapse $\Phi$ intervertebral disc.

I wish to thank Mr. J. B. Pennybacker for his constan help and encouragement in the preparation of this paper? All the cases reported were under his care.

REFERENCES

Dandy, W. E. (1929). Arch. Surg. (Chicago), 19, 66).

- (1942). J. Amer. med. Ass., 119, 474.

Eyre-Brook, A. L. (1952). Brit. J. Surg., 39, 289.

French, J. D. (1946). Surgery, 20, 718.

and Payne, J.T. (1944). Ann. Surg., 120, 73.

$\overline{G a r l a n d, ~ H ., ~ a n d ~ T a v e r n e r, ~ D . ~(1953) . ~ B r i t . ~ m e d . ~ J ., ~ I, ~} 1405$

Kaplan, A., and Umansky, A. L. (1951). Amer. J. Surg., 81, 2620 Kennedy, F., Hyde, B., and Kaufman, S. (1948). J. nerv. ment Dis., i08, 32.

Mixter, W. J., and Barr, J. S. (1934). New Engl. J. Med., 211, 210. I Nicaud, P. (1947). Sem. Hôp. Paris, 23, 2065.

O'Connell, J. E. A. (1944). Surg. Gynec. Obstet., 79, 374.

- (1950). Ann . roy. Coll. Surg. Engl., 6, 403.

Rouques L., David, M., and Pautrat, J. (1948). Bull. Soc. med. Hôp. Paris, 64, 18.

Schneider, R. C. (1949). J. Bone Jt Surg., 31 A, 566.

Stookey, B. (1927). Arch. Neurol. Psychiat. (Chicago), 17, $151 . \quad \mathrm{N}$ Tolosa, E., and Ectors, L. (1953). Acta neurol. psychiat. belg., 53, $\mathrm{W}$ Ver Brugghen, A. (1945). Surg. Gynec. Obstet., 81, 269. 